\title{
An Unusual Cause of Severe Hyponatraemia
}

\section{Hanafy $A^{1}$, Holmes $S^{2}$, Rajeswaran $C^{2}$}

1 The Leeds Teaching Hospitals NHS Trust 2 The Mid Yorkshire Hospitals NHS Trust

\section{Introduction:}

Testosterone replacement therapy is the standard treatment for hypogonadism. However, there are also serious side effects which clinicians should be aware of. Here we present a case of unusual side effect related to testosterone therapy.

\section{Case History:}

- A 90 year-old gentleman attended A\&E with gradually worsening confusion and dyspnoea. His breathing had deteriorated in the last week with marked decrease in exercise tolerance.

- On clinical examination, his BP was $170 / 110 \mathrm{mmHg}$. He had bilateral lower limb oedema. Chest examination showed bilateral decrease in air entry on both bases with expiratory wheeze, JVP was raised. There was no focal neurology.

- Investigations (table 1 ) revealed severe hyponatraemia ( Na $113 \mathrm{mmol} / \mathrm{L}$ ). CXR (figure 1) showed signs of fluid overload. No signs of ischaemia on ECG.

\section{Past History:}

- 4 months prior to admission he had multiple vertebral osteoporotic fractures which led to diagnosis of hypergonadotrophic hypogonadisms (table 1). 18 days before admission, he was commenced on 20 mg Tostran ${ }^{\circledR}$ $2 \%$ gel to treat his hypogonadism.

- Other past history includes hiatus hernia for and mildly impaired LV systolic function.

\section{Medications:}

Lansoprazole, Paracetamol, Ibuprofen, Gabapentin and Tostran $2 \%$ gel

\section{Management:}

Hypervolaemic hyponatraemia secondary to heart failure was diagnosed. $1 \mathrm{~L}$ fluid restriction and IV diuretics (for 6 days) had failed to improve sodium level. However 48 hours after discontinuation of testosterone, heart failure symptoms and signs had improved dramatically and sodium concentration increased by $11 \mathrm{mmol} / \mathrm{L}$ (Figure 2).

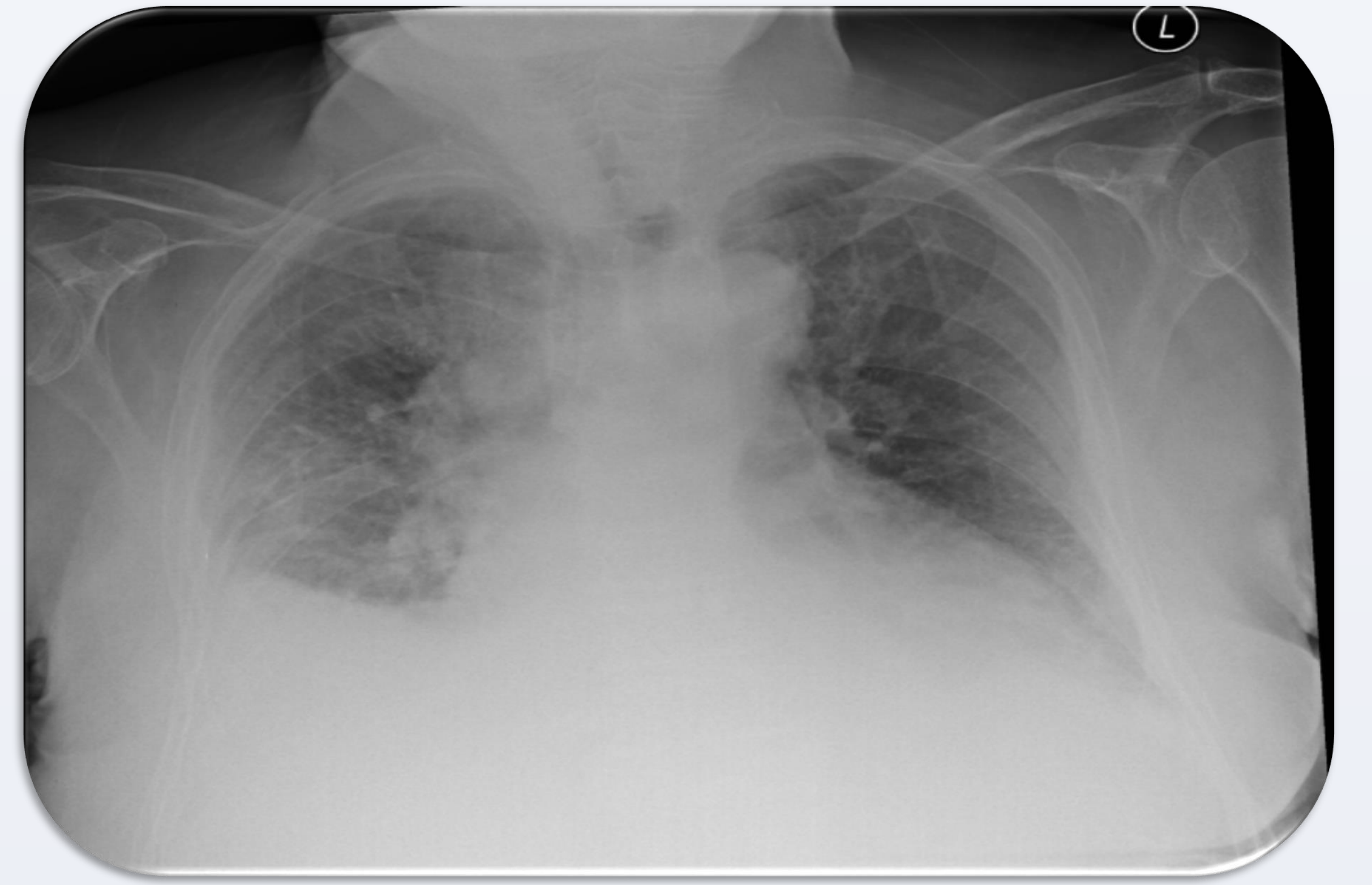

Figure 1: CXR on Admission Showed illdefined airspace opacification within both lower zones. There is evidence of cardiomegaly

\begin{tabular}{|llll}
\hline Table 1: Investigations & & \\
\hline & Before starting Tostran & At time of admission \\
\hline Hb (g/L) & 123 & 93 \\
\hline HCT & 0.354 & 0.251 \\
\hline Na+ (mmol/L) & 132 & 113 \\
\hline K+ (mmol/L) & 4.6 & 4.6 \\
\hline Urea (mmol/L) & 6.0 & 3.9 \\
\hline Creatinine (umol/L) & 64 & 51 \\
\hline Testosterone (nmol/L) & 4.8 & 17.2 \\
\hline LH (U/L) & 30.5 & Not measured \\
\hline FSH (U/L) & 20.9 & Not measured \\
\hline PSA (ug/L) & 0.6 & 1.3 \\
\hline Other Tests & & CRP $8 \mathrm{mg} / \mathrm{L}$ \\
& & POsm: $240 \mathrm{mosm} / \mathrm{kg}$ \\
& & $U_{\mathrm{Na}}:<20 \mathrm{mmol} / \mathrm{L}$ \\
& & $U_{\text {Osm }}: 335 \mathrm{mosm} / \mathrm{kg}$ \\
& & Cortisol: $405 \mathrm{nmol} / \mathrm{L}$ \\
& & Urine PCR: $42 \mathrm{mg} / \mathrm{mmol}$ \\
& & TSH: $8.79 \mathrm{mU} / \mathrm{L}$ \\
& & fT4: $17.4 \mathrm{pmol} / \mathrm{L}$
\end{tabular}

Discussion:

Testosterone can cause fluid retention. Endocrine society recommends against testosterone therapy in men with uncontrolled heart failure. Some studies have however revealed that testosterone improves exercise capacity but not ejection fraction in hypogonadal men with heart failure.

\section{Conclusion:}

Careful risk and benefit assessment should be conducted before commencing testosterone replacement in elderly patients with heart failure.
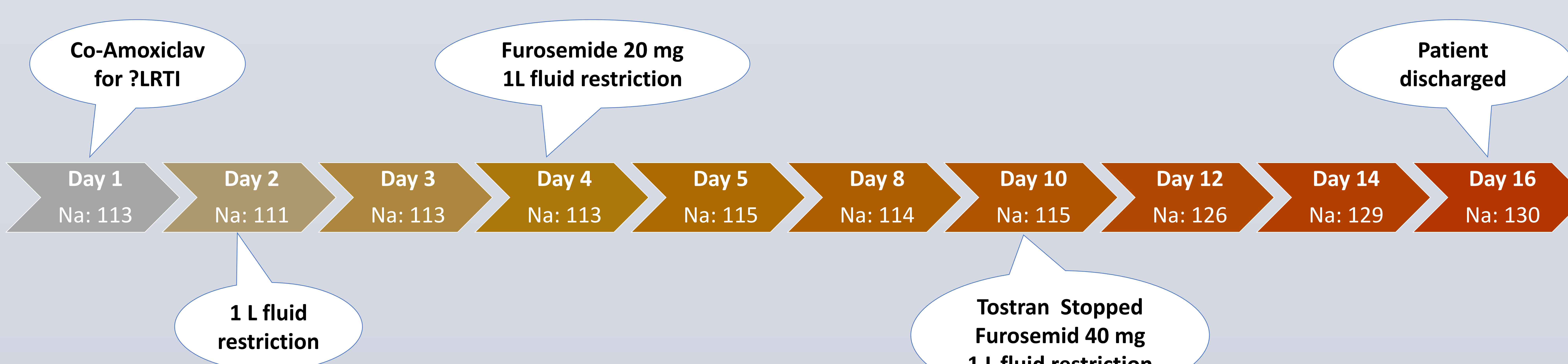

Figure 2: Treatment Progress

\section{References:}

1. Bhasin, S., Brito, J., Cunningham, G., Hayes, F., Hodis, H., Matsumoto, A., Snyder, P., Swerdloff, R., Wu, F. and Yialamas, M. (2018). Testosterone Therapy in Men With Hypogonadism: An Endocrine Society* Clinical Practice Guideline. The Journal of Clinical Endocrinology \& Metabolism, 103(5), pp.1715-1744

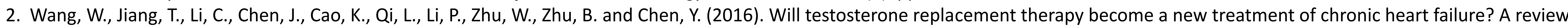
based on 8 clinical trials. Journal of Thoracic Disease, 8(5), pp.E269-E277.

3. Rhoden, E. and Morgentaler, A. (2004). Risks of Testosterone-Replacement Therapy and Recommendations for Monitoring. The New England Journal of Medicine, 350, pp.482-492. 